\title{
14. Modismos na História da Medicina
}

\author{
Joffre Marcondes de Rezende
}

\section{SciELO Books / SciELO Livros / SciELO Libros}

REZENDE, J. M. Modismos na História da Medicina. In: À sombra do plátano: crônicas de história da medicina [online]. São Paulo: Editora Unifesp, 2009, pp. 137-150. História da Medicina series, vol. 2. ISBN 978-85-61673-63-5. https://doi.org/10.7476/9788561673635.0015.

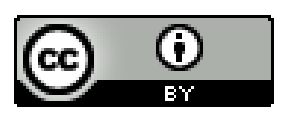

All the contents of this work, except where otherwise noted, is licensed under a Creative Commons Attribution 4.0 International license.

Todo o conteúdo deste trabalho, exceto quando houver ressalva, é publicado sob a licença Creative Commons Atribição 4.0.

Todo el contenido de esta obra, excepto donde se indique lo contrario, está bajo licencia de la licencia Creative Commons Reconocimento 4.0. 


\title{
I4
}

\section{Modismos na História da Medicina*}

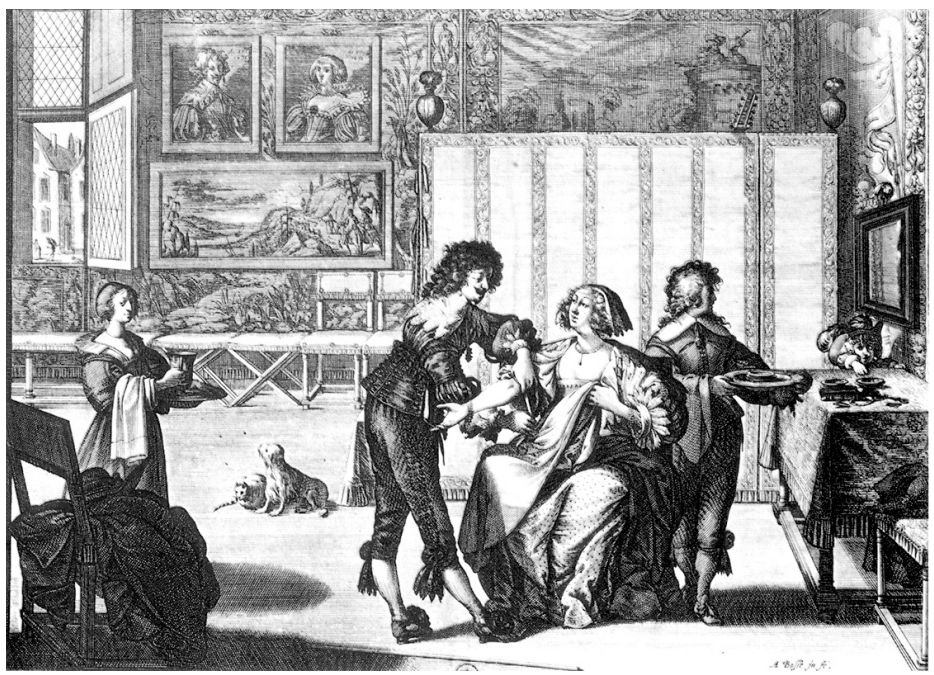

Sangria, remédio para todos os males.

\begin{abstract}
A medicina já foi definida como "um conjunto de verdades provisórias". Por isso mesmo ela se presta a mudanças de conceitos e condutas, na dependência do seu estágio de desenvolvimento e do embasamento teórico de que dispõe para fundamentar a prática médica. Por outro lado, por mais científica e técnica que ela seja, jamais consegue desvencilhar-se do seu componente de subjetivismo. Torna-se, assim, campo fértil para o aparecimento de modismos.

"Modismo" vem de moda e traduz a preferência coletiva por determinadas práticas, costumes ou maneira de pensar e de agir. Na História da Medicina encontramos modismos que atravessaram milênios, ao lado de outros de breve duração; modismos limitados a um povo ou a determinada área geográfica e outros que tiveram aceitação universal; modismos intermitentes que surgiram, desapareceram e renasceram sob nova aparência.

O primeiro deles que gostaríamos de mencionar, por sua importância e universalidade, é a sangria.
\end{abstract}

* Adaptado do livro do autor, Vertentes da Medicina, São Paulo, Giordano, 200 I, pp. 37-50. 
Todos os povos, de todas as latitudes, e em todas as civilizações, utilizaram-se da sangria como terapêutica polivalente em quase todas as doenças. Inicialmente como um ritual impregnado de conteúdo místico e posteriormente sob o fundamento de doutrinas que justificavam tal prática, ou que foram elaboradas para que a justificassem (Seigworth, I980, pp. 2022-2028). Usou-se e abusou-se da sangria.

Outra variante da sangria consistia na aplicação de sanguessugas. As sanguessugas (Hirudo medicinalis) são anelídeos que vivem em águas estagnadas, represas e lagos, e que se alimentam de sangue de animais que penetram nessas águas. São dotadas de uma ventosa na extremidade proximal, por onde sugam o sangue; cada exemplar pode sugar entre Io e I $5 \mathrm{ml} \mathrm{de}$ sangue. Foram muito utilizadas em substituição à sangria.

No início do século XIX o comércio de sanguessugas constituía uma atividade bastante lucrativa, sobretudo na Europa. A França, em um único ano (I833), importou cerca de 40 milhões de sanguessugas para tratamento das mais diversas enfermidades (Enciclopédia Portuguesa e Brasileira, 1958 , p. го9; Lyons e Petrucelli, I978, p. 513).

Outra panaceia de aceitação universal, que perdurou até o início do século $\mathrm{xx}$, foi o do uso de purgativos e clisteres. Desde a medicina egípcia que se acreditava ser o intestino uma via natural de eliminação da materia morbi, ou seja, de substâncias nocivas ao organismo (Tamayo, I988, p. 75). As fezes, por outro lado, sempre foram vistas como excrementos tóxicos, capazes de envenenar o sangue. A ideia de "intoxicação", como consequência da prisão de ventre, ainda perdura no entendimento das pessoas menos esclarecidas. Ouvimos, frequentemente, de pessoas simples, o termo "intoxicado" como sinônimo de "obstipado".

O uso sistemático da sangria, dos purgativos e clisteres foi objeto de acerbas críticas por parte de escritores, dramaturgos e artistas, que nos legaram sátiras irreverentes sobre essa terapêutica polivalente. A mais célebre delas se deve a Molière, na comédia intitulada O Doente Imaginário. Nesta peça há uma cena em que o novo médico recebe o grau de doutor após sua aprovação no exame final.

"Clysterium donare, postea seignare, ensuita purgare", diz o examinando em latim, como era costume na época ("Dar clister, depois sangrar, em seguida purgar"). 


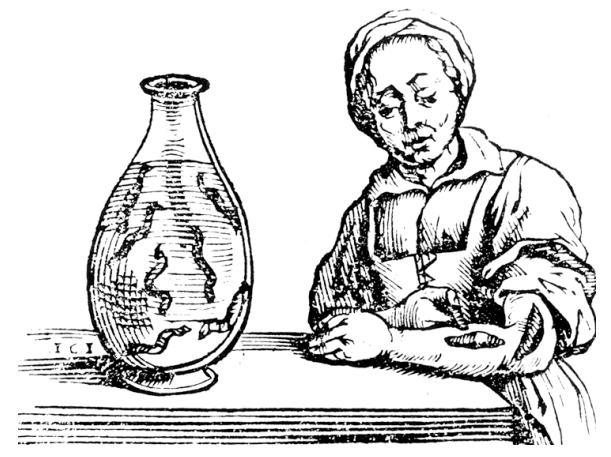

O emprego de sanguessugas, por Willem van den Bossche, 1638.

"Bene, bene, bene respondere. Dignus, est intrare in nostro docto corpore" ("Sois digno de entrar em nossa douta corporação"), replicam os examinadores. Depois de jurar estar sempre de acordo com os colegas mais velhos, é-lhe conferido o direito de "medicar, purgar e sangrar", impune por toda a Terra (Molière, 2002, pp. I60-165).

O uso periódico de purgativo com a finalidade de "limpeza" ainda perdura entre os leigos, o que poderia ser interpretado, à luz dos ensinamentos de Freud, como desejo inconsciente de uma catarse, no sentido psicanalítico do termo.

A ventosa constituiu outro recurso de que se socorria a medicina no passado para o tratamento das mais diversas doenças, especialmente aquelas do aparelho respiratório, como a pneumonia e a pleurisia. A ideia de que a aplicação de ventosas no tegumento cutâneo exerce ação antiflogística nas vísceras subjacentes perdurou até cinquenta anos atrás. Usavam-se ventosas secas e sarjadas, estas últimas produzidas após escarificação da pele.

A sucção pelo vácuo determinava o aparecimento de uma grande mancha roxa de contorno circular, quando a ventosa era seca, e de um grande coágulo sanguíneo no interior do recipiente, quando se praticava previamente a escarificação. A doença seguia o seu curso e se este era favorável todo êxito era creditado à ventosa. A ventosa continua sendo utilizada, ainda que mais raramente, na chamada "medicina alternativa" (Amosson, s.d.).

Alguns modismos são revivescências de práticas que remontam às antigas civilizações. É o caso das fontes hidrominerais como recurso terapêutico. Mesmo admitindo-se que as águas minerais possam ter algum valor terapêuti- 
co, é forçoso reconhecer que o prestígio das “estações de águas" tem oscilado no curso da história entre períodos de esplendor e períodos de esquecimento.

$\mathrm{O}$ uso das fontes hidrominerais teve o seu apogeu na medicina grega, de onde se transferiu para o Império Romano. Após um período de declínio de seu uso, voltou a ganhar prestígio a partir do século XIX (Castiglioni, I947, pp. 472-474), constituindo modismo obrigatório para as classes de maior renda na belle époque que antecedeu a Primeira Guerra Mundial (I9I4-I9I8). Os pacientes de baixa renda que não pudessem frequentar as mais famosas estações hidrominerais, poderiam adquirir pelo correio os sais retirados dessas águas a fim de refazê-las em seu próprio domicílio, conforme documentam anúncios publicados na imprensa médica da época. O desenvolvimento da crenoterapia levou algumas faculdades de medicina, em diversos países, a incluir o estudo das águas minerais ou crenologia no currículo do curso médico. A crença no poder terapêutico das "estações de água", como se denominava a permanência durante um certo período nos locais das fontes hidrominerais, arrefeceu após a Segunda Guerra Mundial e atualmente, com raras exceções, em alguns países onde a publicidade dirigida mantém a credibilidade na sua ação terapêutica, as estâncias minerais nada mais representam que atrações turísticas e opções de lazer, tendo perdido quase por completo a mística do seu poder curativo e todo o ritual que acompanhava a sua utilização.

Alguns modismos recidivantes renascem ao longo da história, ressurgindo aqui e ali sob roupagem e técnicas diferentes. Exemplo típico é o do emprego da sugestão, do poder hipnótico. Situado nos limites da ciência com o charlatanismo, tornou-se um instrumento de fácil manejo pelos charlatães, curandeiros e benzedores, na exploração da credulidade popular. Um dos surtos mais impressionantes ocorreu sob o disfarce de doutrina científica no final do século xviıI com o nome de mesmerismo.

Franz Mesmer ressuscitou a prática da "imposição das mãos", conhecida desde os tempos bíblicos, sob o fundamento de uma nova teoria por ele desenvolvida, que chamou de "magnetismo animal". Segundo essa teoria, todo ser vivo possui fluido magnético que pode ser aproveitado na cura das doenças. Sua doutrina tornou-se muito popular na França e Mesmer ganhou somas fabulosas. Não podendo atender individualmente a todos os que o procuravam, realizava sessões coletivas em que o fluido magnético se transmitia através da água acidulada colocada em uma tina. 
Entre os seus clientes contavam-se eminentes políticos e toda a aristocracia, inclusive Maria Antonieta e o próprio rei Luís XVI, que lhe ofereceu a soma de dez mil francos para fundar o Instituto Magnético.

A Revolução Francesa de I 789 obrigou-o a deixar a França e transferir-se para a Suíça, perdendo todos os seus bens. Sua doutrina, entretanto, continuou a ter seguidores entre médicos e pensadores ilustres, atraindo todos aqueles com tendência para o místico e o sobrenatural. Da França, o mesmerismo passou para a Inglaterra e chegou ao continente americano. O descrédito do mesmerismo decorreu da proliferação de impostores e charlatães, que se diziam magnetizadores e que usavam os mais diferentes processos para ludibriar os incautos (Castiglioni, op. cit., pp. I04-I07).

É interessante observar como as crenças religiosas e os sistemas filosóficos exerceram influência na interpretação da natureza das doenças e na prática da medicina. A ideia de que as doenças mentais estivessem vinculadas a maus espíritos valeu os tratamentos mais desumanos aos pacientes. Foi somente no início do século XIx, depois dos trabalhos de Valsalva e Pinel, que os distúrbios mentais passaram a ser considerados como doenças ligadas ao sistema nervosos central e os doentes deixaram de ser acorrentados ou confinados em condições desumanas (Guthrie, I947, pp. 454-456).

No século XVII duas concepções filosóficas se digladiavam, reivindicando, cada uma delas, a primazia na interpretação dos fenômenos biológicos e patológicos - a iatrofísica e a iatroquímica. Para os iatrofísicos todas as manifestações vitais decorriam de fenômenos físicos ou mecânicos e a vida nada mais seria que o resultado do movimento, passível de ser reduzida a fórmulas matemáticas. As doenças, por sua vez, seriam mera expressão da quebra da harmonia dos fenômenos físicos. Para os iatroquímicos a vida seria o resultado de combinações e reações químicas e todas as doenças deveriam ser tratadas quimicamente (Entralgo, I954, pp. I75-I 84).

Ambas as escolas tinham sua parcela de razão. Os iatroquímicos, contudo, influenciaram mais fortemente a terapêutica, introduzindo numerosas substâncias no tratamento das doenças, sobretudo compostos metálicos de mercúrio $(\mathrm{Hg})$, arsênio (As), antimônio (Sb), bismuto (Bi) e ferro (Fe).

Alguns destes compostos tiveram sua utilidade comprovada no decorrer do tempo, enquanto outros foram abandonados por sua ineficácia ou toxicidade. Dentre estes últimos cumpre destacar o cloreto mercuroso ou 
calomelano, usado como purgativo e antisséptico intestinal, e que produziu mais vítimas do que as doenças que intentava curar.

Há modismos que nascem ao acaso, de uma observação fortuita, e se transformam em sistema que encontra seguidores e defensores por toda parte. Foi o que ocorreu, por exemplo, com a homeopatia. Christian Friedrich Samuel Hahnemann, fundador da homeopatia, viveu de I 755 a I843. A ideia da homeopatia surgiu-lhe por ter apresentado reação febril após fazer uso da quina. Ora, raciocinou ele, se a quina é usada para combater a febre e é capaz de produzir febre, então devemos usar substâncias que produzam quadros semelhantes aos das doenças que desejamos combater. Daí a divisa Similia similibus curantur, ou seja, a terapêutica deve basear-se nos semelhantes e não nos contrários. Sua teoria foi muito ridicularizada na época.

Hahnemann acreditava que os efeitos de um medicamento aumentam à medida que reduzimos as doses; daí surgiu a teoria da potenciação ou dinamização pela diluição progressiva. Tratando-se de líquidos, por exemplo, duas gotas de extrato vegetal são diluídas em 98 gotas de álcool; uma gota desta nova solução é diluída em 99 gotas de álcool e assim sucessivamente, até o máximo de trinta diluições (Hahnemann, I98I, p. 224).

Ele condensou toda a sua doutrina em um livro publicado em I 8 Io sob o título de Organon. Para ele todas as doenças crônicas seriam consequência de três causas: a sífilis, a sicose e a psora, esta considerada um miasma responsável por "incontáveis formas de moléstias" (Idem, p. I07). Muitos de seus continuadores, entretanto, ignoraram esta singular nosografia e conservaram apenas o princípio dos semelhantes e das dinamizações.

O sucesso da homeopatia decorreu, provavelmente, do fato de não causar dano ao paciente, permitindo sua recuperação espontânea, ao contrário da polifarmácia que imperava no século XIx, na qual figuravam muitos medicamentos tóxicos e de eficácia duvidosa.

Ralph Major, em seu livro A History of Medicine, de I954, diz textualmente: "a homeopatia não somente caiu no vazio como praticamente desapareceu. A pedra fundamental da homeopatia, os experimentos de Hahnemann em si próprio e seus amigos são em grande parte ilusórios, conforme demonstraram os farmacologistas. Cada estudante de medicina, farmácia e química sabe atualmente que a potência de uma droga diminui e não aumenta com a diluição" (Major, I954, p. 697). 
As previsões de Major, no entanto, não se confirmaram. Após um perído de declínio a homeopatia ressurgiu, revitalizada, nas últimas décadas e atualmente é reconhecida em muitos países como especialidade médica. No Brasil foi incluída no rol das especialidades médicas pelo Conselho Federal de Medicina em I980.

Um capítulo da história da medicina fértil em modismos tem sido o das dietas. A preocupação com as dietas como meio de tratamento das enfermidades remonta às antigas civilizações. $\mathrm{Na}$ medicina grega a dieta assumiu trascendental importância. Galeno dava grande importância à dieta, tanto no tratamento como na prevenção das doenças.

Em todas as épocas houve sempre a tendência de prescrever uma dieta restritiva aos enfermos, até o mínimo da dieta hídrica e de jejum absoluto, adotada para os pacientes febris. A dieta de jejum só foi derrubada no século XIX por Graves, o mesmo que descreveu o bócio tóxico. Graves expressou o desejo de que em seu epitáfio constassem as seguintes palavras: "ele alimentou os febricitantes" (Castiglioni, op. cit., p. 244).

Certas dietas são claramente influenciadas por hábitos alimentares, os quais variam com a época e com a cultura de um povo. Como bem expressou o prof. Luiz de Paula Castro, a propósito das dietas utilizadas no tratamento da úlcera péptica, "os alimentos constituintes das dietas usadas em gastroenterologia o são mais por força da tradição, e mesmo do folclore e da crendice popular, que por qualquer razão científica" (Castro, I977).

Assistimos atualmente um renovado interesse pelas dietas vegetariana e macrobiótica. Sem negar valor a qualquer tipo de dieta é preciso, entretanto, evitar os procedimentos extremados, que constituem os modismos e que nenhum benefício trazem à saúde.

A obesidade tem sido, através dos tempos, uma fonte inesgotável de modismos no que diz respeito à melhor maneira de perder peso. Regimes alimentares os mais variados, exercícios programados, massagens, anorexigênicos, hormônio tiroidiano etc. Como dizia com senso de humor o prof. José Schermann, de saudosa memória, duas verdades fundamentais, contudo, deixam de ser ditas em todos os métodos de emagrecimento: a de que só se consegue emagrecer pela redução da ingestão calórica e a de que as únicas glândulas responsáveis pela obesidade, na grande maioria das vezes, são as glândulas salivares. Assistimos, atualmente, o emprego de balões e de 
intervenções cirúrgicas com o fim de restringir a capacidade do estômago nos casos rotulados de obesidade mórbida. Ainda não se podem prever as consequências futuras de tais métodos.

Há modismos que decorrem do próprio avanço dos recursos diagnósticos postos à disposição da prática médica. Exemplo típico é o das visceroptoses, resultado da descoberta dos raios-X ao final do século XIX, que permitiu a visualização das vísceras abdominais com o paciente de pé. Como ressaltou Barclay, em I936, os médicos estavam habituados a mentalizar a posição das vísceras de acordo com os livros de anatomia e não se cuidou de obter padrões de normalidade com o novo método (Smith, I982).

Verificou-se que a topografia e a disposição dos órgãos ao exame radiológico diferia das posições indicadas nos livros de anatomia, e mais ainda, que havia diferenças importantes entre os indivíduos. Concluiu-se, precipitadamente, por uma correlação entre os sintomas apresentados pelos pacientes e as posições anômalas das vísceras. A gastroptose ou "estômago caído" passou a ser responsável por toda espécie de dispepsia; a hepatoptose por disfunções hepáticas; a coloptose por obstipação intestinal; o ceco móvel e a nefroptose, por qualquer manifestação dolorosa no flanco e na fossa ilíaca direita. Inventaram-se cintas apropriadas para levantar o estômago, para manter o rim direto na sua loja, para impedir a descida do cólon transverso. E quando o paciente não obtinha os resultados desejados recorria-se ao tratamento cirúrgico - às pexias: gastropexia, colopexia, nefropexia, histeropexia, no sentido de restabelecer a pretensa topografia anatômica de cada órgão.

A essa interpretação simplista, herdeira da medicina iatrofísica do século XVII, sucedeu a medicina constitucionalista, que procurava correlacionar o comportamento biológico e as próprias doenças à constituição do indivíduo e ao seu biótipo. Surgiram as classificações biotipológicas com a descrição de tipos morfológicos e os seus correspondentes perfis dinâmico-humorais.

O longilíneo astênico seria mais sujeito aos distúrbios funcionais do aparelho digestivo, à úlcera péptica, à tuberculose, enquanto os brevilíneos estênicos seriam predispostos às doenças cardiovasculares, aos distúrbios metabólicos, como a obesidade, o diabetes e a gota. Embora haja um fundo de verdade na biotipologia, os adeptos da medicina constitucionalista levaram ao extremo a importância dos fatores genéticos no determinismo da patologia humana (Berardinelli, I942, pp. 363-37I). 
A essa visão biogenética seguiu-se uma nova onda que se tornou modismo no século xx: a da medicina psicossomática.

Depois de Freud, a neurose passou a ser considerada como o fator fundamental, não somente dos distúrbios funcionais, como das próprias doenças orgânicas. A úlcera péptica, a hipertensão arterial, a asma brônquica, as coronariopatias, bem como doenças de etiologia desconhecida, como a retocolite ulcerativa inespecífica, passaram a ser explicadas como consequência das situações emocionais de estresse. O sistema nervoso autônomo seria o elo intermediário entre a mente e os órgãos efetores (Sullivan e McKell, I950, p. I 5 ).

Após os trabalhos de Alexander, na década de I930, a psicanálise foi considerada o tratamento indicado para a úlcera péptica.

Em todos os movimentos que se tornam moda na conduta médica há sempre um princípio de verdade. O entusiasmo excessivo por uma ideia é que conduz a uma visão unilateral e deformada da realidade, contra a qual deve o médico se precaver. Somente o tempo e a postura crítica diante dos fatos conseguem reduzir a novidade à sua verdadeira dimensão.

Outro modismo que documenta esta assertiva é o da infecção focal, que imperou na primeira metade do século xx. Vários estados mórbidos passaram a ser atribuídos à existência de um foco de infecção que deveria ser localizado e removido. Tendo algum fundamento científico, em virtude dos conhecimentos adquiridos sobre a patogenia da febre reumática e da glomerulonefrite aguda, a teoria da infecção focal foi levada às últimas consequências (Billings, I930, pp. 760-773). Quaisquer que fossem as queixas ou as mazelas do paciente, punha-se o médico, qual um detetive, a procurar um foco de infecção, ao qual pudesse imputar todo o quadro mórbido, fosse ele caracterizado por dores reumáticas, febre de causa ignorada, extrassistolia, anemia ou estado depressivo.

Muitos dentes foram extraídos e muitas amígdalas operadas, assim como trompas e apêndices removidos, a fim de retirar possíveis focos de infecção.

Alguns modismos resultaram de analogias nem sempre verdadeiras. Como se conhecia, por exemplo, a ação hormonal do extrato de tiroide dessecada, nada mais lógico do que a utilização de extratos de outras glândulas e órgãos no tratamento das deficiências, reais ou presumidas, das glândulas e órgãos correspondentes. Surgiu, assim a opoterapia, que 
incluía desde o extrato hepático e o extrato do estômago de porco, aos extratos de suprarrenais, ovários e testículos (Major, op. cit., p. 78I). A indústria de tais produtos conseguiu envolver o nome de um pesquisador respeitável que foi Brown Sequard. Tais preparados, quase sempre utilizados por via oral, eram, na verdade, destituídos de ação. O seu uso entrou em declínio depois que se comprovou a sua ineficácia e assim que foram isolados os hormônios em sua forma pura.

Há doenças que constituem verdadeiros modismos, tanto o médico se vale do diagnóstico fácil que se encontra na moda, como o doente aceita com tranquilidade o rótulo que o médico lhe oferece. Tal é o caso, por exemplo, da colite, termo vago e de natureza imprecisa, muito utilizado no passado para designar os casos de padecimentos abdominais de qualquer natureza.

Axel Munthe, no seu extraordinário O Livro de San Michele, nos conta como era bem aceito o diagnóstico de "colite" pela clientela das grandes capitais europeias - uma doença compatível com uma longa vida e que garantia ao seu portador o direito de reivindicar maior atenção. Muitos dos casos então rotulados de "colite" correspondem ao que passou a ser designado por cólon irritável, cólon espástico, neurose cólica ou, mais recentemente, intestino irritável (Munthe, s.d., pp. 36-44).

A descoberta, no início de século $\mathrm{xx}$, da responsabilidade do apêndice nos processos supurativos da fossa ilíaca direita, rotulados até então de "peritiflite”, despertou um súbito interesse pela remoção do apêndice, fazendo surgir a discutida entidade da "apendicite crônica" como causa de todos os males, impondo a apendicectomia sistemática em todo paciente com queixas abdominais (Paula e Silva, I943, pp. 359-400).

Depois que os termos em "ite" se restringiram aos processos inflamatórios bem definidos do ponto de vista anatomopatológico, surgiu a ideia dos distúrbios funcionais de natureza motora e secretora para explicar os quadros clínicos mal definidos. O conceito das discinesias ganhou nova dimensão e a vesícula hipocinética, popularmente chamada de "vesícula preguiçosa", passou a ser a bengala de apoio dos hipocondríacos e a figurar nas conversas elegantes dos acontecimentos sociais.

Mais elegante, entretanto, do que ter a vesícula preguiçosa, é "sofrer do fígado". O fígado tornou-se uma espécie de Pedro Malazartes, ao qual se atribuíam todas as mazelas, desde a cefaleia à obstipação intestinal. 
O prof. Waldemar Berardinelli, há alguns anos, escreveu um artigo com muito senso de humor, sob o título de "O Fígado Nacional", no qual ele demonstra que o povo brasileiro é o que mais diz sofrer do fígado em todo o mundo. Segundo o prof. Heitor Rosa são três as paixões do brasileiro: futebol, carnaval e "sofrer do fígado". E a indústria farmacêutica sabe disso, pelo volume de vendas diretas ao consumidor, nas farmácias, de "remédios para o fígado". A maioria de tais medicamentos traz em sua fórmula as mais esdrúxulas composições, predominando em geral a mistura de um pretenso antitóxico com um fator lipotrópico e um laxativo.

Ultimamente a preocupação com o fígado tem declinado e está sendo substituída pela gastrite e pelo refluxo gastroesofágico. Raro é o paciente com queixas dispépticas que não as atribua à gastrite. Por sua vez, o refluxo tem centralizado a atenção tanto dos médicos, como dos leigos; mesmo sem comprovação, tem sido responsabilizado por distúrbios mal definidos dos aparelhos digestivo e respiratório.

Ao final do século xx assistimos, também, ao ressurgimento da prática da limpeza do cólon, agora com o nome de colonterapia ou hidroterapia do cólon, sob o fundameno da existência de toxinas fecais que ficam retidas no cólon e que devem ser eliminadas (Ernst, 1997, pp. I96-198). Embora sem a aprovação da medicina oficial, centenas de clínicas espalhadas por vários países se dedicam a este procedimento. Utilizam moderna tecnologia, com aparelhos automáticos que injetam e aspiram através de sonda introduzida no reto, cinquenta a sessenta litros de água. Do folheto de uma destas clínicas transcrevemos as seguintes indicações, que chegam a ser folclóricas, tais como "prisão de ventre, flatulência; em processos de desintoxicação; estresse, cansaço, irritabilidade; auxiliar no tratamento da pele (acne); prevenção do câncer do intestino; enxaquecas etc.”.

A ginecologia e obstetrícia têm sido um campo fértil de modismos. Exemplifiquemos com o trabalho de parto.

A parturição, por ser um acontecimento marcante na biologia da mulher e na perpetuação da vida humana, tem dado origem aos mais variados procedimentos e atitudes, ao sabor dos costumes dos povos e das concepções vigentes em cada época.

Nos povos primitivos, tal como ainda em muitas tribos indígenas, o parto é considerado um fenômeno natural, sujeito, entretanto, a complicações fa- 
tais. O desejo de auxiliar a parturiente deu origem à idealização de diversas manobras com o fim de facilitar e abreviar o parto. Tais manobras, muitas vezes, em lugar de diminuir, aumentavam o sofrimento da mulher.

Os primeiros livros de obstetrícia escritos no século Xvi foram dedicados às "comadres", como eram chamadas as parteiras de baixo nível cultural, uma vez que era interdito ao homem assistir ao parto. No ano de I 522 , na cidade de Hamburgo, um médico que se vestiu de mulher para assistir a um parto foi descoberto e pagou com a vida a sua ousadia, tendo sido queimado vivo (Graham, I957, pp. I9I-I94).

Ultrapassado o obscurantismo da Idade Média e vencidas as barreiras preconceituosas, os médicos e cirurgiões passaram a ser admitidos nos cuidados às parturientes, o que fez com que se acentuasse a tendência intervencionista no trabalho de parto, inicialmente com o emprego do fórceps e, após a descoberta da anestesia e o advento da assepsia, com a operação cesariana.

Assistimos hoje ao modismo das cesarianas. As gestantes recebem bem a operação cesariana como maneira de suprimir a dor e preservar sua própria anatomia. O obstetra, por sua vez, no atual sistema de trabalho, que exaure suas energias no dia a dia da profissão, nem sempre tem condições de acompanhar um parto horas a fio, noite a dentro, suportando pressões dos familiares que pedem insistentemente ao doutor "para dar um jeito". E a cesárea é a solução. Por vezes, chega a ser programada previamente como opção bilateral.

Sempre houve, entretanto, uma corrente favorável ao parto natural, desde a escola de Viena, no século XviII. Percebe-se, atualmente, uma reação salutar nesse sentido em nosso país, uma volta à natureza, tal como vem ocorrendo em relação à amamentação materna, para desgosto das indústrias do leite em pó.

O mais recente modismo é o ressurgimento da auto-hemoterapia. A auto-hemoterapia consiste na retirada de sangue em uma das veias da prega do cotovelo (em geral to ml) e sua injeção intramuscular na região deltoide ou na região glútea. As injeções são repetidas a intervalos de cinco a sete dias. O método se baseia na pretensa ação estimuladora das células sanguíneas no sistema imunitário do paciente. Foi utilizado inicialmente na França, de onde se difundiu para outos países. No Brasil foi empregado na primeira metade do século xx por alguns eminentes cirurgiões como tratamento auxiliar no pós-operatório (Teixeira, 1924, pp. 213-230). Ressurgiu como panaceia 
universal de uso popular com grande alarde e tal entusiasmo, que levou o Conselho Federal de Medicina e a Sociedade Brasileira de Hematologia e Hemoterapia a se pronunciarem contra essa prática por absoluta falta de comprovação científica.

Além dos modismos de responsabilidade médica há os modismos da medicina popular, dita alternativa, que surgem a cada dia e que sobrevivem por um tempo variável, até serem substituídos por outros, como ocorreu com o confrei (Symphytum officinale), de comprovada ação cicatrizante quando usado externamente, porém de ação hepatotóxica em preparados de uso interno, e com o ipê roxo (Tabebuia heptaphylla), cuja casca teria propriedades anticancerígenas (Roitman, I98 I, p. 944).

Há modismos inofensivos, porém há modismos que acarretam um grande potencial de risco, como os psicotrópicos, cujo consumo vem aumentando assustadoramente. A depressão tornou-se a doença da moda. É um equívoco pensar que a solução da angústia humana está na farmacologia do sistema nervoso.

Muitos outros tipos de modismos poderiam ser citados. Longe de nós, entretanto, a pretensão de esgotar o assunto; moveu-nos tão somente o propósito de enumerar alguns exemplos que nos ajudem a refletir sobre as vicissitudes da prática médica; lançar uma visão para o passado, pensando no futuro.

Também não tivemos a intenção de ser negativistas. Não há razão para negativismos. O progresso da medicina é real e contínuo. A prática da medicina não mais se baseia em hipóteses e sim em comprovações experimentais.

A expectativa de vida tem aumentado nas últimas décadas, em consequência, sobretudo, das ações preventivas de saúde; dispomos, hoje, de maiores recursos diagnósticos e terapêuticos do que no passado; muitas doenças estão praticamente erradicadas, enquanto outras estão sob controle. Graças aos antibióticos já não se morre tão facilmente de doenças infecciosas, como a pneumonia e a febre tifoide. $\mathrm{O}$ avanço da cirurgia foi de tal ordem que os doentes já não aceitam a eventualidade de um insucesso e temem mais o risco anestésico do que o ato cirúrgico em si.

Há, ainda, o espectro do câncer, as doenças cardiovasculares, as endemias próprias do subdesenvolvimento e, sobretudo, as desigualdades sociais que impedem que todos os povos e todas as pessoas tenham livre acesso às conquistas da ciência e da tecnologia, colocadas a serviço da saúde. 


\section{Referências Bibliográficas}

Amosson, B. “Cupping”. Disponível em http://altmed.creighton.edu/Cupping/History.htm.

Berardinelli, W. Tratado de Biotipologia e Patologia Constitucional. Rio de Janeiro, Livraria Francisco Alves, I942.

Billings, F. "Focal Infection as the Cause of General Diseases". Bulletin of the New York Academy of Medicine, 6 (I2), I930, pp. 760-773.

Castiglioni, A. História da Medicina. São Paulo, Cia. Editora Nacional, 1947.

CAstro, L. P. "Existe Base Racional para o Emprego da 'Dieta Branda' no Tratamento da Úlcera Péptica?”. Revista da Associação Médica Brasileira, 23 (I) , pp. 32-34, I977.

Entralgo, P. L. Historia de la Medicina. Barcelona, Editorial Científico Médica, I954.

ERnst, E. “Colonic Irrigation and the Theory of Autointoxication: a Triumph of Ignorance over Science”. Journal of Clinical Gastroenterology, 24(4), pp. I96-I98, I997.

Graham, H. Surgeons all. New York, Philosophical Library, I957.

Guthrie, D. Historia de la Medicina. Barcelona, Salvat, I947.

Hahnemann, S. Organon da Arte de Curar. São Paulo, Associação Paulista de Homeopatia, I98I.

Lyons, A. S. \& Petrucelli, R. J. Medicine: An Illustrated History. New York, Harry N. Abrams, 1978.

Major, R. H. A History of Medicine. Oxford, Blackwell Scientific Publications, I954.

Molière. O Doente Imaginário. Belo Horizonte, Crisálida, 2002.

Munthe, A. O Livro de San Michele. Lisboa, Edição Livros do Brasil, s./d.

Paula e Silva, G. S. "O Problema da Apendicite Crônica”. Gastroenterologia Clínica, Rio de Janeiro, A Casa do Livro, I943.

Roitman, I. N. "Comfrey and liver damage”. The Lancet, abr. 25, I98 I.

Seigworth, G. R. "Bloodletting over the centuries". York State Journal of Medicine, pp. 2022-2028, dez. I980.

Smith, L. L. "Sir Arbuth Lane, Chronic Intestinal Stasis, and Autointoxication". Annals of Internal Medicine, 96, pp. 365-369, I982.

Sullivan, A. J. \& McKell, T. C. Personality in Peptic Ulcer. Springfield, Charles C. Thomas, I950.

Tamayo, R. P. EI Concepto de Enfermedad. México, Consejo Nacional de Ciencia y Tecnologia, I988.

Teixeira, J. “Complicações Post-operatórias. Contribuição à sua Prophylaxia”. BrasilCirúrgico, 2 (3), pp. 213-230, I940. 